\title{
Thermally buffered microhabitats recovery in tropical secondary forests following land abandonment
}

Pamela González del Pliego ${ }^{1 *}$, Brett R. Scheffers ${ }^{2}$, Edmund W. Basham ${ }^{3}$, Paul Woodcock ${ }^{4}$, Charlotte Wheeler ${ }^{5}$, James J. Gilroy ${ }^{4,6}$, Claudia A. Medina Uribe ${ }^{7}$, Torbjørn Haugaasen ${ }^{4}$, Rob P. Freckleton ${ }^{1}$, David P. Edwards ${ }^{1}$

${ }^{1}$ Department of Animal and Plant Sciences, University of Sheffield, S10 2TN, UK.

2Department of Wildlife Ecology \& Conservation, Newins-Ziegler Hall, University of Florida/IFAS, Gainesville, FL 32611, USA.

${ }^{3}$ Department of Geography, University of Sheffield, S10 2TN, UK.

${ }^{4}$ Department of Ecology and Natural Resource Management, Norwegian University of Life Sciences, Ås, 1430 Norway.

${ }^{5}$ Department of Geography, University College London, WC1E 6BT, London, UK.

${ }^{6}$ Department of Environmental Sciences, University of East Anglia, NR4 7TJ, UK.

${ }^{7}$ Instituto de Investigación de Recursos Biológicos Alexander von Humboldt, Bogotá Calle 28A \# 15-09, Colombia.

*Corresponding author: pgonzalezdelpliegocastaneda1@sheffield.ac.uk 


\begin{abstract}
Given the dramatic loss of tropical forests and accelerating climate change, secondary forest regeneration is increasingly recognised as being an important method for reversing losses in biodiversity and carbon stocks. The recolonisation of biodiversity within secondary forests depends upon the recovery of forest structure, including the range of microhabitats used by diverse communities. Here, we investigate the return of critical microhabitats along a successional gradient of secondary forest in the Tropical Andes of Colombia. We measured the abundance of live (bromeliads, tree ferns and moss) and dead (deadwood and leaf litter) microhabitats across three landscapes, each encompassing primary, and young and old secondary forests. Considering the increasing rate of climate warming in the region, we also explored whether these microhabitats provide thermally buffered microclimates. We found that secondary forests have different composition and lower complexity of microhabitats than primary forests, but that the abundance of bromeliads and deadwood recover towards primary levels. Each microhabitat reduces exposure to extreme temperatures, serving as thermal buffers by reducing maximum and increasing minimum temperatures among all forest types. These benefits exist despite ambient temperatures in secondary forests surpassing those of primary forests by $1-2^{\circ} \mathrm{C}$ on average. The protection of secondary forest and promotion of further forest regrowth in the Tropical Andes should represent an urgent investment for conservation, and the value of these secondary forests for offering critical microhabitats and buffered microclimates under climate change should not be overlooked.
\end{abstract}

\title{
Keywords:
}

Carbon enhancement • Choco-Andes • microclimate buffering • global climate change • secondary forest regeneration 


\section{Introduction}

Land-use change is a primary driver of global biodiversity loss (MEA 2005) and carbon emissions (Grace, Mitchard et al. 2014). During the 1980s and 1990s, more than 80 million hectares (ha) of tropical forests were converted into cropland and pasture (Gibbs, Ruesch et al. 2010), with the rate of conversion since increasing in many tropical regions (Hansen, Potapov et al. 2013). The conversion of tropical forest to agriculture severely fragments the landscape, dramatically reducing species richness (Foster, Snaddon et al. 2011; Gibson, Lee et al. 2011), and causing severe edge and isolation effects that further increases extinction risk (Ferraz, Russell et al. 2003; Schnell, Harris et al. 2013).

Despite these trends, during the past decades in some regions of the tropics there has been a concurrent phase of land abandonment in areas of marginal suitability for agriculture (Guariguata and Ostertag 2001; Sanchez-Cuervo and Aide 2013). Seventy percent of land abandonment occurs in hilly or montane areas of Central America, the Andes, Vietnam, and the Philippines (Asner, Rudel et al. 2009), but also occurs in flat regions such as the Amazon and Madagascar (Asner, Rudel et al. 2009; Rodríguez, Armenteras et al. 2012).

Following land abandonment, natural forests begin to regenerate in these areas, with residual seed banks and dispersed seeds underpinning this process (Lindsell, Lee et al. 2015). Over time, carbon stocks in secondary forests gradually recover towards levels found in primary forests (Martin, Newton et al. 2013; Gilroy, Woodcock et al. 2014). Secondary forests are also (re-)colonized by organisms (Martin, Newton et al. 2013; Gilroy, Woodcock et al. 2014; Queiroz, Beilin et al. 2014), including species threatened with extinction in some regions (Gilroy, Woodcock et al. 2014).

The precise nature of biodiversity recovery depends on forest structure - the properties that define a forest's general appearance, including foliage density and height, as well as the range of critical small-scale habitat features or microhabitats (MacArthur, MacArthur et al. 1962). Microhabitats are used by a wide range of taxa: Logs and tree cavities provide habitat for amphibians, birds, small mammals, and invertebrates (Stapp 1997; Cadavid, Roman-Valencia et al. 2005; Grüebler, Widmer et al. 2014); epiphytic plants such as bromeliads and bird's nest ferns (Asplenium) offer shelter and breeding habitat for 
amphibian and invertebrate communities (Ellwood and Foster 2004; Urbina and Galeano 2009; Silva, Carvalho et al. 2011; Jocque and Field 2014; McCracken and Forstner 2014; Scheffers, Phillips et al. 2014); and leaf-litter and soil are commonly used by amphibians and invertebrates (Stapp 1997; McGlynn and Kirksey 2000; Cadavid, Roman-Valencia et al. 2005; Urbina and Galeano 2009; Wanger, Iskandar et al. 2010). Microhabitats, along with providing space for breeding and foraging, also provide buffered shelter during extreme weather events, although the latter has only been recorded in primary old-growth forest (Scheffers, Edwards et al. 2014), not secondary forests. Thus, the extent of microhabitat recovery in secondary forests is an unknown but critically important process to biodiversity recovery in these areas.

In addition to land-use change, biodiversity is also threatened by climate change. Over the last 50 years, the rate of warming has increased significantly while extreme weather events (e.g., droughts and heat-waves) have become more frequent and intense (IPCC 2014), severely threatening biodiversity globally (Sekercioglu, Schneider et al. 2008; Chen, Shiu et al. 2009; Chen, Hill et al. 2011; Hannah 2011; Maclean and Wilson 2011; Freeman and Class Freeman 2014). Carbon enhancements under carbon-based payments for ecosystem service schemes (e.g., United Nations Reducing Emissions from Deforestation and Forest Degradation, REDD+), can been implemented to reduce carbon emissions by financially incentivising forest recovery and restoration. Although these programmes offer some positive biodiversity co-benefits (CBD 2011; Gilroy, Woodcock et al. 2014), whether they have a positive impact on microhabitats and microclimates - and thus the species depending on them - is unknown.

Species have limited options in responding to climate change: become extinct; cope or adapt in situ; or shift their ranges to track optimal climates (Lawler, Ruesch et al. 2013), which has already occurred with a large number of species (Parmesan and Yohe 2003; Hickling, Roy et al. 2006). Nonetheless, for the numerous species that are unable to track their optimal climate niches (Chen, Shiu et al. 2009), the presence of microhabitats could provide a microclimatic shelter during extreme weather events. Thus, the ability of microhabitats to buffer increased ambient temperatures in secondary forests will likely determine the survival of these species. 
Here, we aim to answer: (1) How similar is microhabitat composition in secondary forests to that found in primary forests? (2) How much time since land abandonment is required for the recovery of critical microhabitats? (3) Is there a positive relationship between carbon stock recovery and microhabitat recovery? And (4) how well do microhabitats in secondary forests buffer climate compared to primary forests? Here we answer these key questions by focusing on a successional gradient of secondary forest in the Tropical Andes, which is a global hotspot of extinction risk and species endemism.

\section{Methods}

\section{Study area}

We chose three study landscapes located within the departments of Antioquia, Risaralda and Chocó, along the Western cordillera of the Colombian Andes (long: -75.8895 to 76.0825, lat: 5.2396 to 5.8251) (Fig. S1; following (Gilroy, Woodcock et al. 2014)). Each site encompasses primary forests, naturally regenerating secondary forests and an agricultural matrix dominated by cattle pasture, with other crops present under very limited cover $(<10$ hectares in total, including maize and plantations of tamarillo Solanum betaceum (Gilroy, Woodcock et al. 2014). The study area covered an altitudinal range of 1,290-2,680 $\mathrm{m}$ above sea level. This region supports one of the highest global diversities of threatened and endemic taxa (Myers, Mittermeier et al. 2000; Orme, Davies et al. 2005), and is characterised by a long history of cattle farming (Gilroy, Woodcock et al. 2014).

Across these three landscapes (Fig. S1B, from north to south: Reserva Tangaras, Chocó; Reserva Mesenia-Paramillo, Antioquia; and Cerro Montezuma, Risaralda), we created 29 sampling squares of $400 \mathrm{~m} \times 400 \mathrm{~m}$ and spaced by $>400 \mathrm{~m}$ apart, with squares representing one land-use type (naturally-regenerating young secondary forest from 4 to 18 yr old, old secondary forest from 19 to $35 \mathrm{yr}$ old, and primary old-growth forest). In each square, data were sampled from three sampling points, totalling 87 sampling points each spaced by 200 m (following (Gilroy, Woodcock et al. 2014)).

\section{Microhabitats}


We placed a $25 \mathrm{~m} \times 6 \mathrm{~m}$ plot at each of our 87 sampling points, within which we sampled microhabitat abundance. Elevation was measured in the plot centre. We measured three live (bromeliad, fern, moss) and two dead (deadwood, leaf litter) microhabitats across each plot. Logistic field limitations allowed us to have only 74 plots for dead microhabitats and carbon.

Live vegetation:

Bromeliads - Epiphytes are particularly vulnerable to forest degradation (Turner, Chua et al. 1996), but are important microhabitats for amphibians and invertebrates (Jocque and Field 2014; Scheffers, Phillips et al. 2014). Bromeliads are one of the most abundant epiphytes in the Tropical Andes (Benzing 2000). We recorded the total number of bromeliads in our plot. Total number of plots (Ntotal) $=87$ plots.

Tree ferns - Understorey tree ferns (Order Polypodiales) have a single erect trunk and very large fronds, making them important microhabitats for amphibians, mites, spiders and several arthropods including beetles (Shuter and Westoby 1992; Richards 2007; Li, Wang et al. 2011; Fountain-Jones, McQuillan et al. 2012). We measured height and diameter at breast height (dbh) of all ferns $>5 \mathrm{~cm}$ dbh (following (Gilroy, Woodcock et al. 2014). We estimated tree fern biomass using the allometric equation of (Tiepolo, Calmon et al. 2002). Ntotal $=87$ plots.

Moss - Moss is an important microhabitat for insects and amphibians (TarkowskaKukuryk and Mieczan 2014; Lee-Yaw, Sechley et al. 2015). In each plot, we delimited fifteen $1 \mathrm{~m}^{2}$ quadrats (following (Urbina and Galeano 2009)). Moss height and density defines how easy species move through it (Lee-Yaw, Sechley et al. 2015)). Therefore, moss was assessed in such a way as to retain moss original structure during measurement. To do this, we derived a metric of moss volume by multiplying depth (an average of four measurements per quadrat) and the percentage of moss coverage (Maanavilja, Aapala et al. 2014). Ntotal $=15$ quadrats per plot $* 87$ plots $=1,305$ quadrats.

Dead vegetation:

Deadwood - Deadwood is a critical requirement for many arthropod species since it provides a place to hide and forage (Lassauce, Paillet et al. 2011; Bluhm, Scheu et al. 2015), 
while the volume of deadwood can indicate a higher abundance of birds and beetles (Winter, Flade et al. 2005). At each point we established a smaller $15 \mathrm{~m} \times 5 \mathrm{~m}$ plot, within which we estimated the biomass of all standing or fallen dead trees (snags) $>5 \mathrm{~cm}$ dbh (Gilroy, Woodcock et al. 2014). For snags $>10 \mathrm{~m}$ high we used allometric equations to estimate biomass, applying a deadwood density of $0.31 \mathrm{~g} \mathrm{~cm}^{-3}$ taken from the literature (Gibbon, Silman et al. 2010). For snags $<10 \mathrm{~m}$ high, we assumed the tree was a cylinder and estimated biomass by multiplying volume with wood density. The diameter and length of all pieces of fallen deadwood (coarse woody debris) of $\geq 5 \mathrm{~cm}$ dbh was also recorded, converted into volume and used to estimate biomass (assuming a cylindrical shape). Ntotal $=74$ plots.

Leaf litter - Leaf litter is an essential microhabitat for amphibians and invertebrates, providing physical shelter and foraging space (Urbina and Galeano 2009; dos Santos Bastos and Harada 2011; Queiroz, Ribas et al. 2013). We measured litter dry biomass since the amount (weight) of leaf litter is one of the most important characteristics to determine species abundance and richness (e.g. ants (dos Santos Bastos and Harada 2011; Queiroz, Ribas et al. 2013)). Within each smaller $15 \mathrm{~m} \times 5 \mathrm{~m}$ plot, we collected all leaf litter, grass and small plants ( $<0.5 \mathrm{~m}$ in height) from $4 \times 0.25 \mathrm{~m}^{2}$ quadrats within each plot (Gilroy, Woodcock et al. 2014), following (Queiroz, Ribas et al. 2013). We weighed these samples to the nearest $0.1 \mathrm{~g}$, then used the fresh:dry weight ratio of an oven-dried subsample (10-20\%) to estimate the dry biomass of litter (Nascimento and Laurance 2002). Ntotal $=74 \mathrm{~m}^{2}$ quadrats.

\section{Live non-soil carbon stocks}

To calculate live non-soil carbon stocks, within each smaller $15 \mathrm{~m} \times 5 \mathrm{~m}$ plot we also measured the diameter at breast height ( $\mathrm{dbh}$ ) of all live trees $>5 \mathrm{~cm} \mathrm{dbh}$, and measured wood specific gravity using tree cores extracted with an increment borer (two threads, $5.15 \mathrm{~mm}$ diameter; Haglöf, Sweden) (Gilroy, Woodcock et al. 2014). We used these values in four allometric biomass estimation equations taken from harvested tree studies (Chave, Andalo et al. 2005; Alvarez, Duque et al. 2012; Feldpausch, Lloyd et al. 2012). We took the mean of the four estimates as the final aboveground estimate for each tree. Palm growth form differs from that of other trees, and so to calculate palm biomass we measured diameter and estimated height, and then used the allometric equation of (Sierra, del Valle 
et al. 2007). Root biomass was estimated using a published upland forest root:shoot ratio of 0.26 (Cairns, Brown et al. 1997). All vines with a $\mathrm{dbh}$ of $\geq 2 \mathrm{~cm}$ that were $\leq 1 \mathrm{~m}$ from the long edges of the plot were also measured and vine biomass was estimated using an equation developed in Colombian montane forest (Sierra, del Valle et al. 2007). We summed the biomass pools for each plot before multiplying by 0.5 to give an estimate of the total live non-soil carbon stock (Gibbon, Silman et al. 2010). Ntotal = 74 plots.

\section{Temperature data}

We used 179 iButton data loggers (model: DS1921G-F5; accuracy: $0.5{ }^{\circ} \mathrm{C}$ ) to record understorey ambient, canopy and microhabitat temperature, and we also set nine iButton hygrochron loggers (model: DS1923; accuracy: $0.1^{\circ} \mathrm{C}$ ) as a backup to record understorey ambient temperature across all forest types. We placed the iButtons in 17 plots from Cerro Montezuma and 16 plots from Reserva Mesenia-Paramillo, with placement spanning young and old secondary, and primary forests (Table S1). All loggers recorded data every two hours from February 2013 to February 2014.

Each iButton was placed inside a re-sealable zipper storage bag (50 $\mathrm{mm} \mathrm{X50} \mathrm{mm}$ ) to shelter them from precipitation and enclosed within a metal mesh to guard them from rodents. One iButton logger per plot was hung approximately $1 \mathrm{~m}$ above the ground to measure understorey ambient temperature (Scheffers, Brunner et al. 2013). To identify the (near-)maximum potential ambient air temperature for our study plots, we hung a second iButton in the upper canopy cover of trees between ten and thirteen meters above the ground (Scheffers, Phillips et al. 2013), as close as possible to directly above the understorey ambient logger depending on canopy accessibility. To minimize exposure to direct solar radiation, canopy, understorey and humidity loggers were secured under a plastic funnel, with all funnels suspended facing north (controlling for diurnal variation in sun position).

Microhabitat temperature loggers were deployed thus: (1) approximately $5 \mathrm{~cm}$ under leaf litter (ntotal=33); (2) between the leaves of bromeliads (ntotal=26); (3) inside holes at the base of trees (tree circumference $>8 \mathrm{~cm} \mathrm{DBH)} \mathrm{(ntotal=33);} \mathrm{(4)} \mathrm{within} \mathrm{the} \mathrm{roots}$ of ferns (fern circumference $>8 \mathrm{~cm} \mathrm{DBH}$ ) (ntotal=33); and (5) at approximately $20 \mathrm{~cm}$ depth in soil (ntotal=9). All loggers were placed within $8 \mathrm{~m}$ of the understorey ambient logger 
(most within one and four metres). Only one iButton was placed within a particular microhabitat for each plot.

\section{Statistical Analyses}

Microhabitat composition

To compare microhabitat composition among secondary and primary forests we used nonmetric multidimensional scaling ordination (NMDS, function "metaMDS" from the vegan package). This technique uses microhabitat abundance data and makes no prior assumptions about habitat-level structuring in the data. To evaluate whether composition differed significantly across the forest types, we transformed our data into a similarity matrix (Bray-Curtis index) and performed an analysis of similarity (ANOSIM). ANOSIM uses ranks of dissimilarities and this test is free from any normality assumptions. A post-hoc permutation test (999 replications) was run to detect which pairs of groups significantly differed. The community analysis was performed using PRIMER 7 (Version 7.0.7; Clarke, KR, Gorley, RN, 2015). We also extract NMDS axis 1 and 2 to create a microhabitat composition metric.

\section{Microhabitat complexity recovery}

To compare microhabitat data to a notionally common scale we normalized the data for each microhabitat by rescaling the range from 0 to 1 . To create a microhabitat complexity metric we added the normalized data for each microhabitat by forest type. This complexity metric represents a truthful microhabitat abundance value because it sums each microhabitat value, in comparison with the composition metric (derived from NMDS axes) which represents the relationship or similitude of microhabitat data among forest types in a graphical manner. To compare microhabitat complexity of secondary and primary forest, we obtained the ratio of young and old secondary forest complexity compared to primary forest complexity (considering the latter our benchmark of 100 percent). We then performed a one-way analysis of variance (ANOVA; function "aov") with forest type as our grouping variable.

To determine whether there were differences in the abundance of each microhabitat across forest types, we performed linear mixed effect models (function 
"Imer"), with sampling square, elevation, and landscape as random factors. All data were log transformed before each analysis, and residuals were assessed for each model considering model assumptions.

\section{Carbon-microhabitat co-benefits}

Forest structure is a main factor of the global carbon cycle (trees and foliage determining carbon storage and sequestration) (Schulze, Beck et al. 2005; Houghton, Hall et al. 2009). Due to the ecological meaningfulness of carbon and the high correlation between carbon sequestration and forest age, we assessed the relationship between carbon and microhabitat recovery using total live non-soil carbon as our predictive variable. We did so for each of our microhabitats using the normalized microhabitat data, microhabitat complexity metric, and microhabitat composition metric (using NMDS axes 1 and 2). We used quantile regression (function "rq"), from the quantreg package, because our data showed a larger number of outliers than normal, and quantile regressions give more robust estimates against outliers in the response measurements. For the same reason, we analysed the 10th, 50th, and 90th percentile to discover more useful predictive relationships between our variables. All microhabitat data were log transformed prior to analyses.

\section{Microclimates}

Our data showed no seasonality patterns, and therefore was not subdivided. Temperature maxima and minima have been successfully used to measure microhabitat thermal buffering effect (Shi, Paull et al. 2014). Therefore, weekly maximum, minimum and mean temperatures were taken from each iButton per microhabitat per forest type. We used weekly (taking weekly max, min and mean temperatures) models instead of daily models because of their lower AIC values. We used linear mixed effect models ("Ime") to determine temperature differences among forest types, including forest type and date as fixed effects, and as random effect we placed iButton identity nested within transect and elevation (the two landscapes in which we placed iButtons do not overlap in elevation, hence we do not need to include landscape as a random factor). P-values for each model were determined comparing the model versus the null model ("anova"). Significant differences between forest types were assessed via post-hoc Tukey comparisons. 
To obtain the rate of increase in microhabitat temperature for every $1^{\circ} \mathrm{C}$ increase in understorey ambient temperature we used the temperature data collected every 2 hours. Linear models ("Im") were employed to generate a relationship between each microhabitat metric (i.e. bromeliad max, bromeliad min, bromeliad mean, etc.) depending on understorey ambient temperature (ambient max, ambient min, or ambient mean). Residual plots were checked to confirm model assumptions were met. Unless stated otherwise, all statistical analyses were performed in $\mathrm{R}$ (Version 3.1.2).

\section{Results}

\section{Microhabitat composition}

Ordination plots showed that microhabitat composition in secondary forests differed significantly from primary forests (Fig. $1 \mathrm{~A}$; ANOSIM, $R=0.53, p=0.001$ ). There is some degree of overlap in the microhabitat composition between forest types (Fig. 1A), and pairwise comparisons revealed no significant differences between young secondary and old secondary forest $(R=0.05, p=0.25)$. In contrast, there was significant dissimilarity between old secondary and primary forest $(R=0.36, p=0.001)$. In the ordination plot, young secondary forests were the furthest away from primary forests, making them the least similar regarding their microhabitat composition $(R=0.66, p=0.001)$. Recovery of secondary forest thus regenerates increasingly similar microhabitat composition to primary forest over time.

\section{Microhabitat complexity recovery}

Considering bromeliads, tree ferns, moss, deadwood and leaf litter, primary forests held a significantly higher microhabitat complexity than young secondary forests $\left(F_{2,367}=\right.$ $3.57, p<0.05)$, although there was no difference between young and old secondary forest (Fig. 1B). There was, however, no significant difference between young and old secondary forest in their ratio of complexity compared to primary forest (Fig. $1 C ; F_{1,8}=0.07, p=0.79$ ).

Live vegetation - There was a significant difference between forest types in number of bromeliads $(F=36.5, p<0.0001)$ : old secondary had more bromeliads than young secondary forest, and in turn, primary forest had more bromeliads than old secondary (Fig 
S2A). Therefore, secondary forests need more than 35 years of regeneration to fully recover this critical microhabitat. Conversely, there was no significant difference between forest types in tree fern biomass ( $F=1.96, p=0.15$; Fig S2B) or moss volume (Fig S2C; $F=1.32, p=$ 0.27). Thus, even after a short period of time ( 4 to 18 years) of forest regeneration, tree ferns and moss volume were recovered.

Dead vegetation - There was significant variation between forest types in deadwood $(F=8.57, p<0.001)$ : Young secondary forests (which did not differ significantly from old secondary forests) had less deadwood volume than primary forest (Fig S2D). Nevertheless, old secondary forest had accumulated almost half (44\%) of the total deadwood volume found in primary forests just 35 years post-land abandonment (Fig S2D). Leaf litter volume did not differ significantly between forest types ( $F=5.54, p=0.02$; Fig S2E), thus this critical microhabitat recovered even in early stages of forest regrowth.

\section{Carbon-microhabitat co-benefits}

Live vegetation - Bromeliad abundance showed a positive relationship with carbon stock increase. They increased significantly with carbon stock at the $10^{\text {th }}(t=4.79, p<$ $0.001), 50^{\text {th }}(t=3.78, p<0.001)$, and $90^{\text {th }}(t=2.54, p=0.01)$ quantiles (Table 1; Fig. 2A). Tree fern biomass and moss volume showed no significant relationship with carbon stock at any of the quantiles (Table 1; Fig. 2C).

Dead vegetation - Deadwood volume recovery showed a positive relationship with carbon stock increase. Deadwood volume increased significantly with carbon at the $10^{\text {th }}(\mathrm{t}=$ 2.97, $p=0.003), 50^{\text {th }}(t=2.08, p=0.04)$, and $90^{\text {th }}(t=4.4, p<0.001)$ quantiles (Fig. $\left.2 D\right)$. Conversely, there was no relationship between leaf litter volume and carbon stock at any of the quantiles ( $p>0.19$; Table 1 ; Fig. 2E).

Microhabitat complexity and composition - Microhabitat complexity showed a positive increase with carbon at the $50^{\text {th }}$ quantile $(t=2.82, p=0.005)$, whereas the $10^{\text {th }}$ and $90^{\text {th }}$ quantiles showed no relationship ( $>0.80, p>0.20$; Table $1 ;$ Fig. 2F). Microhabitat composition derived from NMDS axis 1 showed a negative relation with carbon at the $10^{\text {th }}(t$ $=-4.23, \mathrm{p}<0.001), 50^{\text {th }}(\mathrm{t}=-4.36, \mathrm{p}<0.001)$, and $90^{\text {th }}(\mathrm{t}=-2.82, \mathrm{p}=0.006)$ quantiles (Table 1; Fig. 2G). Forest types, therefore, can be distinguished by their carbon stock accumulation. 
Conversely, there was no relationship between NMDS axis 2 and carbon stock ( $p>0.19$; Table 1; Fig. 2H).

\section{Microclimates}

The maximum ambient temperature in the understorey was lower than in the canopy in all forest types (Table2; Fig. 3A and 3B). The daily maximum ambient temperature in the understorey of primary forest was cooler than that in young secondary forests ( $z$ value $=$ 2.98, $p=0.007$; Fig. $3 \mathrm{~B} 2$ and 3B4). However, the maximum ambient temperature in the understorey in old secondary forests was not significantly different from primary or young secondary forests ( $p>0.29$; Table2).

Daily maximum temperatures within microhabitats were on average cooler than understorey ambient and canopy, whereas the daily minimum temperature within microhabitat was on average warmer than understorey and canopy ambient (except for bromeliads) (Fig. 3C). Thus, these microhabitats are reducing exposure and serving as thermal buffers by keeping cooler temperatures when it is warm and warmer temperatures when it is cold. During the day, microhabitats thermally buffered the understorey ambient temperature maxima by $0.78^{\circ} \mathrm{C}$ to $2.27^{\circ} \mathrm{C}$ in primary forest, by $0.38^{\circ} \mathrm{C}$ to $2.15^{\circ} \mathrm{C}$ in old secondary forest, and by $1.67^{\circ} \mathrm{C}$ to $2.31^{\circ} \mathrm{C}$ in young secondary forest. At night, microhabitats buffered the understorey ambient temperature minima by $0.07^{\circ} \mathrm{C}$ to $0.23^{\circ} \mathrm{C}$ in primary forest and by $0.64^{\circ} \mathrm{C}$ to $0.97^{\circ} \mathrm{C}$ in old secondary forest. In young secondary forest, only leaf litter and tree holes were warmer than understorey ambient night-time temperature by $0.09^{\circ} \mathrm{C}$ and $0.54^{\circ} \mathrm{C}$, respectively (Table2; Fig. 3). In contrast, soil minimum and mean temperature was significantly lower in primary and old secondary forests compared to young secondary forests ( $p>0.04$; (Table2; Fig. 3G). All microhabitats warmed at a slower rate $\left(<1^{\circ} \mathrm{C}\right.$ microhabitat : $1^{\circ} \mathrm{C}$ ambient) than understorey ambient (Table2; Fig. 3).

\section{Discussion}

The regrowth of secondary forest on abandoned farmlands is prevalent across the tropics, and these forests are important for biodiversity and carbon stock recovery (Gilroy, Woodcock et al. 2014). Our study suggests that as abandoned lands regenerate as forests, 
their functional value also increases through the accumulation and diversification of critical microhabitats. Specifically, we document a chronological recovery of microhabitat complexity and a general trend toward niche diversification in older secondary forests. While we found that forest types have different microhabitat composition, secondary forest approached primary forest levels of microhabitat complexity over time. In turn, recovered microhabitats buffered against extreme low and high temperatures in a similar manner to those in primary forest, suggesting positive carbon-microhabitat co-benefits as forests regrow. Thus, investment to protect or enhance carbon stocks in secondary forests under carbon-based payments for ecosystem services (PES, e.g., REDD+) will also support an abundance of thermally buffered microhabitats.

\section{Microhabitat composition}

Our study indicates that microhabitat composition in primary forests varies greatly from secondary forests. The extent to which secondary forests support biodiversity is strongly linked to the presence and abundance of critical microhabitats (Michel and Winter 2009). Young and old secondary forests have similar microhabitat composition, suggesting that even from early stages of forest development some microhabitats are already available for biodiversity (Cadavid, Roman-Valencia et al. 2005; Urbina-Cardona, Olivares-Pérez et al. 2006).

\section{Microhabitat complexity recovery across habitat types}

We found a highly variable yet predictable recovery of microhabitats across forest types (Bittner and Breckle 1995; Oldekop, Bebbington et al. 2012; Woziwoda, Parzych et al. 2014). Nevertheless, microhabitat complexity in our study recovered chronologically from young to old secondary forests and this increase in ecological complexity has documented benefits for vertebrates and invertebrate diversity and abundance even in young secondary forests (Lassauce, Paillet et al. 2011; Jocque and Field 2014; Scheffers, Phillips et al. 2014; Bluhm, Scheu et al. 2015). As such, our study provides strong support for allocating secondary growth forests as an important conservation tool for recovering biodiversity and reversing extinction risk (Chazdon 2014; Queiroz, Beilin et al. 2014). 
There is a clear transition from young secondary forests rich in moss and leaf litter to bromeliad and deadwood-rich primary forests. Importantly, bromeliad and deadwood levels in secondary forest reach almost half of those found in primary forest within 35 years following land abandonment (Fig. S2A and S2D). The high elevation of our study sites likely supports a faster recovery rate of bromeliads than lower altitude forests. For example, we found similar recovery rates as the Venezuelan Andes (Barthlott, Schmit-Neuerburg et al. 2001), whereas lowland rainforests in Panama (140 m a.s.l.) have not shown any epiphytic recovery after 35 years of forest growth (Woods and DeWalt 2013). Such a dichotomy probably reflects bromeliad requirements for cooler, wetter climates like the Andes in comparison with seasonal and hotter lowlands (Ruiz, Martinson et al. 2012). As amplifiers of biodiversity, bromeliad recovery in secondary forests may offer additional niche space. Bromeliad abundance and deadwood volume are strongly linked to forest age (Barthlott, Schmit-Neuerburg et al. 2001; Woods and DeWalt 2013; McGarvey, Thompson et al. 2015), and translocation of bromeliads into medium-aged secondary forests may be a useful tool in applied forest management.

\section{Linking forest carbon and microhabitat recovery}

Climate change scenarios predict increasing temperatures and variable rainfall in the Tropical Andes, which may hinder forest and microhabitat recovery (IPCC 2014). Carbonbased PES initiatives seek to maximize carbon storage and sequestration as part of a global scheme for climate change mediation, but may also offer important co-benefits for localized biodiversity conservation (Strassburg, Kelly et al. 2010; Phelps, Friess et al. 2012; Gilroy, Woodcock et al. 2014). However, to our knowledge, we have for the first time showed a strong positive relationship between carbon stock and microhabitat complexity, which underpins ecological resilience and increases the benefits to biodiversity (CBD 2011). Forest resilience is strong in secondary forests along the Neotropics (from Mexico to Chile), where they show high carbon sequestering potential and great carbon storage (Poorter, Ongers et al. 2016). Although, secondary forests have lower carbon stocks and biodiversity than primary forests (Poorter, Ongers et al. 2016), their recovery may now be linked to microhabitat complexity recovery. This also underscores that the Tropical Andes, which is a global hotspot of endemism and extinction risk, are of great interest for promoting carbon enhancements via natural forest regeneration, given that it would be cheap to do so in this 
region (see (Gilroy, Woodcock et al. 2014)), and that such projects would offer strong carbon, microhabitat, and biodiversity benefits (Gilroy, Woodcock et al. 2014).

\section{Are secondary forests climate change ready?}

Microhabitats in secondary forest showed temperature-buffering abilities similar in magnitude to those found in primary forests, suggesting that all forest types provide species with climate microrefugia. The low rate of temperature increase in microhabitats also shows that species are thermally protected for longer periods of time under extreme temperature increases than would otherwise be the case in understorey ambient temperatures (see also (Scheffers, Edwards et al. 2014) for primary forests). Our findings suggest that microhabitats will become an increasingly important resource to help ectotherm communities mitigate the negative impacts of climate change (Huey and Tewksbury 2009), especially in the Tropical Andes where extreme weather events have become more intense and frequent and overall temperatures have increased (Ruiz, Martinson et al. 2012).

Of concern, much tropical montane vegetation depends on specific environmental characteristics to thrive and is highly sensitive to climate change (Morueta-Holme, Engemann et al. 2015). Thus climate change could negatively affect the abundance of critical living microhabitats, and perhaps more so in recovering secondary forests. For instance, mosses and bromeliads need constant moisture to grow (Nadkarni 2000; Merrifield and Royce 2002), such that a drastic decline in moisture could reduce their abundance, and as a consequence, threaten many bird, amphibian and invertebrate species (Merrifield and Royce 2002; Panizzo 2011; Scheffers, Phillips et al. 2014; Silva and Piratelli 2014).

\section{Survey limitations}

Our study sites are restricted to naturally regenerating secondary forests in an agricultural matrix dominated by pasture. Therefore, we cannot expand our results to other agricultural systems. For example, different taxa (e.g. birds and arthropods) are affected differently in coffee than in oil palm plantations (Edwards, Magrach et al. 2014; Jordani, Hasui et al. 2015). Our results are restricted to secondary forests near a primary forest, thus source-sink dynamics could have improved microhabitat and species recovery (Barlow, Gardner et al. 
2007; Gibson, Lee et al. 2011). Whether similar recovery would occur in isolated secondary forests and whether microhabitat recovery would be so rapid in other ecosystems outside of the Tropical Andes, especially in hotter and drier lowlands, are both critical unanswered questions.

\section{Conclusions}

Old secondary forests have high carbon storage potential, and our results suggest that the abundance of critical microhabitats in secondary forests is recovering, sometimes to levels found in a primary forest. Higher abundance of microhabitats increases landscape resilience by returning structure to forests and as such enhances ecological integrity (Ruiz-Jaen and Aide 2004). This provides habitat for biodiverse communities, including many species at risk of extinction. While protecting primary forests remains a critical conservation goal (Gibson, Lee et al. 2011), we live in an era of increasingly human-dominated tropics (Lewis, Edwards et al. 2015). The protection or promotion of secondary forest regrowth is often a more economically feasible strategy of protecting microhabitat rich and climate change resilient forests as opposed to preserving primary forests, which retain extremely valuable timber stocks (Fisher, Edwards et al. 2011). The critical role of secondary forests should not be overlooked as we seek solutions to the biodiversity crisis, both now and under future climate change. 


\section{Acknowledgments}

We thank Fernando Forero and other staff from the Instituto de Investigación de Recursos Biológicos Alexander von Humboldt for logistical support. For field access permission, we thank Fundación Colibrí (Reserva Natural Mesenia-Paramillo), Fundación ProAves (Reserva Las Tangaras), and Leopoldina Tapasco (Cerro Montezuma). We thank Gustavo Suárez, Uriel Rendón, Luis Rendón, Antonio Largo, Uberne García, and Anderson Moreno for help with fieldwork and logistics. Funding was provided to T.H. and D.P.E. by the Research Council of Norway, grant number 208836; P.G.C. was supported by CONACYT, Scholarship 359063. This is article \#10 of the Biodiversity, Agriculture, and Conservation in Colombia (Biodiversidad, Agricultura, y Conservación en Colombia [BACC]) project

\section{References}

They will go here when I remove the endnote links. 
Table legends

Table 1. Carbon-microhabitat co-benefits. Summary from quantile regressions at the $90 \%$, $50 \%$, and $10 \%$ quantiles from abundances of five microhabitats (Fig. $2 \mathrm{~A}-\mathrm{H}$ ), microhabitat complexity as the sum of all normalized microhabitat data, and microhabitat complexity derived from NMDS axes scores (see Fig. 1), along a gradient of young secondary forest, old secondary forest, and primary forest in the Colombian Andes. Bold $p$ values represent significant relationships $(p<0.05)$. See text for detailed methods.

Table 2. Mean comparisons of daily maximum, daily mean, and daily minimum environmental temperature, and the rate of temperature increase for every $1^{\circ} \mathrm{C}$ increase in understorey ambient temperature per forest type. Values shown are mean \pm SE. Superscripts reveal pairwise differences at $p<0.05$. Key to abbreviations: PF, primary forest; OSF, old secondary forest (19 - 35 yr); YSF, young secondary forest (4 - 18 yr). 
Table 1.

\begin{tabular}{|c|c|c|c|}
\hline Microhabitat & quantile & t value & $p$ value \\
\hline & $90 \%$ & 2.54 & 0.01 \\
\hline \multirow[t]{3}{*}{ Bromeliad } & $50 \%$ & 3.78 & $<0.001$ \\
\hline & $10 \%$ & 4.79 & $<0.001$ \\
\hline & $90 \%$ & 0.34 & 0.73 \\
\hline \multirow[t]{3}{*}{ Tree fern } & $50 \%$ & 1.18 & 0.24 \\
\hline & $10 \%$ & 0.77 & 0.44 \\
\hline & $90 \%$ & -0.60 & 0.54 \\
\hline \multirow[t]{3}{*}{ Moss } & $50 \%$ & -0.46 & 0.64 \\
\hline & $10 \%$ & 1.02 & 0.30 \\
\hline & $90 \%$ & 4.00 & $<0.001$ \\
\hline \multirow[t]{3}{*}{ Deadwood } & $50 \%$ & 2.08 & 0.04 \\
\hline & $10 \%$ & 2.97 & 0.003 \\
\hline & $90 \%$ & -0.49 & 0.62 \\
\hline \multirow[t]{3}{*}{ Leaf litter } & $50 \%$ & 0.06 & 0.94 \\
\hline & $10 \%$ & -1.29 & 0.19 \\
\hline & $90 \%$ & 0.80 & 0.42 \\
\hline \multirow[t]{3}{*}{ Complexity } & $50 \%$ & 2.82 & 0.005 \\
\hline & $10 \%$ & 1.27 & 0.20 \\
\hline & $90 \%$ & -4.23 & $<0.001$ \\
\hline \multirow{3}{*}{$\begin{array}{l}\text { Composition } \\
\text { NMDS axis } 1\end{array}$} & $50 \%$ & -4.36 & $<0.001$ \\
\hline & $10 \%$ & -2.82 & 0.006 \\
\hline & $90 \%$ & -0.94 & 0.34 \\
\hline \multirow{2}{*}{$\begin{array}{l}\text { Composition } \\
\text { NMDS axis } 2\end{array}$} & $50 \%$ & -0.45 & 0.65 \\
\hline & $10 \%$ & 1.31 & 0.19 \\
\hline
\end{tabular}


Table 2.

\begin{tabular}{|c|c|c|c|c|c|c|c|}
\hline & $\begin{array}{l}\begin{array}{l}\text { Forest } \\
\text { type }\end{array}\end{array}$ & PF & OSF & YSF & L. ratio & $p$ & df \\
\hline \multirow{4}{*}{ Canopy } & Max & $20.19 \pm 0.09$ & $21.06 \pm 0.01$ & $21.71 \pm 0.12$ & 21.72 & $<0.001$ & 458 \\
\hline & Mean & $16.46 \pm 0.04$ & $16.82 \pm 0.04$ & $16.86 \pm 0.05$ & 51.39 & $<0.001$ & 458 \\
\hline & Min & $14.21 \pm 0.03$ & $14.31 \pm 0.03$ & $14.22 \pm 0.04$ & 16.39 & $<0.001$ & 458 \\
\hline & Rate & 1.368 & 1.362 & 1.140 & & & \\
\hline \multirow{4}{*}{$\begin{array}{c}\text { Understorey } \\
\text { ambient }\end{array}$} & Max & $18.78 \pm 0.06^{\mathrm{B}}$ & $19.79 \pm 0.07^{\mathrm{AB}}$ & $20.18 \pm 0.09^{A}$ & 57.85 & $<0.001$ & 2054 \\
\hline & Mean & $16.60 \pm 0.04$ & $17.29 \pm 0.04$ & $16.87 \pm 0.05$ & 110.60 & $<0.001$ & 2054 \\
\hline & Min & $14.95 \pm 0.04$ & $15.43 \pm 0.04$ & $15.58 \pm 0.05$ & 61.58 & $<0.001$ & 2054 \\
\hline & Rate & - & - & - & & & \\
\hline \multirow{4}{*}{ Bromeliad } & Max & $18.00 \pm 0.06$ & $19.41 \pm 0.07$ & $18.39 \pm 0.08$ & 30.64 & $<0.001$ & 1009 \\
\hline & Mean & $16.02 \pm 0.04$ & $17.07 \pm 0.04$ & $15.85 \pm 0.05$ & 36.61 & $<0.001$ & 1009 \\
\hline & Min & $14.45 \pm 0.04$ & $15.25 \pm 0.04$ & $13.94 \pm 0.05$ & 6.18 & 0.102 & 1009 \\
\hline & Rate & 0.927 & 0.901 & 0.754 & & & \\
\hline \multirow{4}{*}{ Tree fern } & Max & $16.51 \pm 0.04$ & $18.04 \pm 0.03$ & $18.23 \pm 0.06$ & 33.36 & $<0.001$ & 1350 \\
\hline & Mean & $15.72 \pm 0.04$ & $17.06 \pm 0.03$ & $16.70 \pm 0.05$ & 120.16 & $<0.001$ & 1350 \\
\hline & Min & $15.02 \pm 0.04$ & $16.10 \pm 0.03$ & $15.45 \pm 0.06$ & 25.95 & $<0.001$ & 1350 \\
\hline & Rate & 0.463 & 0.473 & 0.546 & & & \\
\hline \multirow{4}{*}{ Tree hole } & Max & $16.54 \pm 0.03$ & $17.64 \pm 0.03$ & $17.87 \pm 0.03$ & 12.07 & 0.03 & 1413 \\
\hline & Mean & $15.87 \pm 0.04$ & $17.05 \pm 0.03$ & $16.92 \pm 0.03$ & 175.43 & $<0.001$ & 1413 \\
\hline & Min & $15.18 \pm 0.04$ & $16.40 \pm 0.03$ & $16.12 \pm 0.04$ & 46.44 & $<0.001$ & 1413 \\
\hline & Rate & 0.448 & 0.356 & 0.303 & & & \\
\hline \multirow{4}{*}{ Leaf litter } & Max & $16.85 \pm 0.04$ & $18.24 \pm 0.05$ & $18.51 \pm 0.05$ & 15.09 & 0.01 & 1384 \\
\hline & Mean & $15.91 \pm 0.04$ & $17.12 \pm 0.04$ & $16.89 \pm 0.04$ & 87.48 & $<0.001$ & 1384 \\
\hline & Min & $15.05 \pm 0.04$ & $16.07 \pm 0.04$ & $15.67 \pm 0.04$ & 20.86 & $<0.001$ & 1384 \\
\hline & Rate & 0.547 & 0.560 & 0.503 & & & \\
\hline \multirow{4}{*}{ Soil } & Max & $14.83 \pm 0.02$ & $14.79 \pm 0.01$ & $15.71 \pm 0.02$ & 10.42 & 0.06 & 373 \\
\hline & Mean & $14.45 \pm 0.02^{\mathrm{B}}$ & $14.70 \pm 0.01^{\mathrm{B}}$ & $15.45 \pm 0.02^{\mathrm{A}}$ & 9.25 & 0.009 & 1384 \\
\hline & Min & $14.13 \pm 0.02^{B}$ & $14.60 \pm 0.01^{B}$ & $15.20 \pm 0.02^{\mathrm{A}}$ & 11.25 & 0.04 & 1384 \\
\hline & Rate & 0.124 & 0.043 & 0.124 & & & \\
\hline
\end{tabular}


Figure legends (high resolution files available if accepted for publication)

Fig. 1. (A) Nonmetric multidimensional scaling (NMDS) of microhabitat composition among forest types using microhabitat abundance. Young secondary forests are $<19$ years old, old secondary forests are $>19$ years old, and primary forest is undisturbed old-growth. Ellipses represent a grouping function depending on the standard deviation of points with a 95\% confidence interval. (B) Recovery of microhabitat complexity among forest types. (C) Secondary forest ratio of microhabitat complexity compared to primary forest (considered as $100 \%)$. YSF: young secondary forest; OSF: old secondary forest; PF: primary forest. Values represent normalized data from mean abundance of microhabitats. Error bars represent standard error. Different superscripts represent significant differences $(p<0.05)$.

Fig. 2. Carbon and microhabitat co-benefits for bromeliads (A), tree ferns (B), moss (C), deadwood (D), leaf litter (E), and NMDS axis 1 (F). Quantile regressions of microhabitat abundance data between young ( $<19 \mathrm{yr}$ old) secondary forest (yellow points), old (19-35 yr old) secondary forest (orange points), and primary forest (light green points). Lines represent $10^{\text {th }}$ (bottom line), $50^{\text {th }}$ (middle line), and $90^{\text {th }}$ (top line) quantiles. Solid lines represent significant relationships $(p<0.05)$. Dash lines represent non-significant relationships.

Fig. 3. Annual temperature variation recorded every two hours (A1-G1), mean maximum temperature (A2-G2), mean average temperature (A3-G3), and mean minimum temperature (A4-G4) from Feb 2014 to Feb 2015 for canopy (A), understorey ambient (B), bromeliad (C), tree fern (D), tree hole (E), leaf litter (F) and soil (G) along a naturally regenerating young secondary forest (<19 yr; yellow), old secondary forest (19-35 yr; orange), and primary forest (light green) in the Colombian Andes. Error bars represent standard error. Similar superscripts represent no significant differences $(p<0.05)$. 
Fig. 1
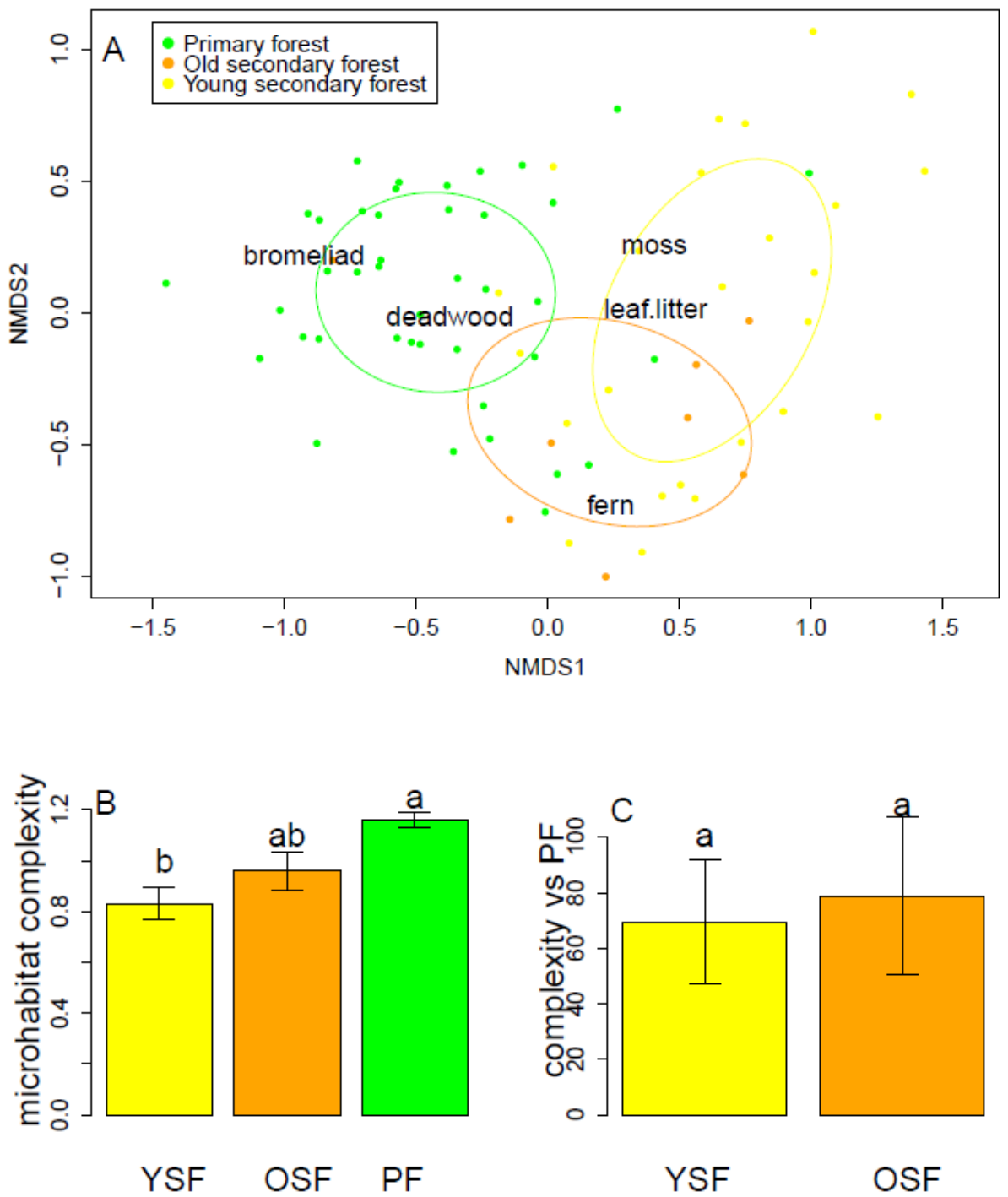
Fig. 2
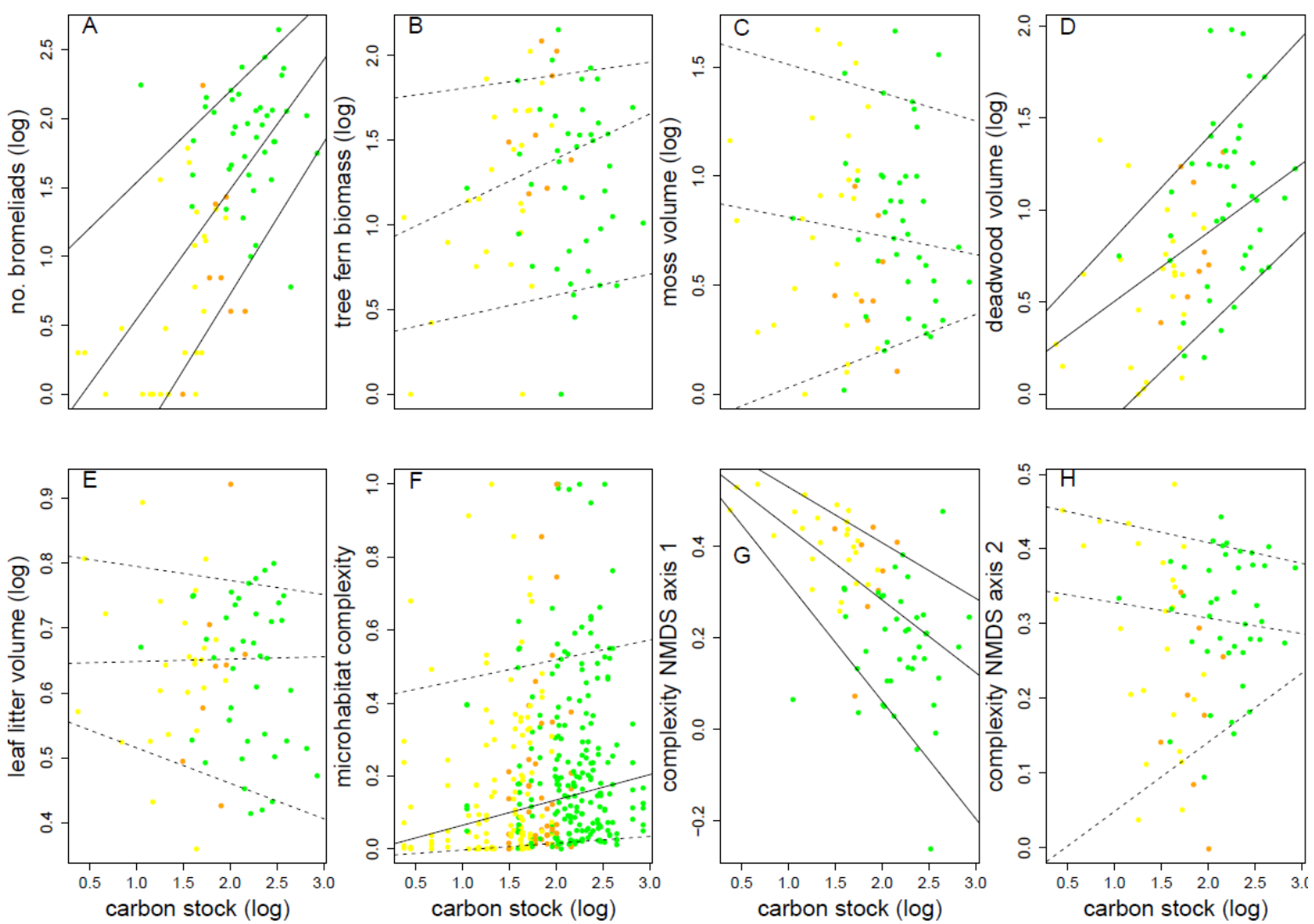
Fig. 3
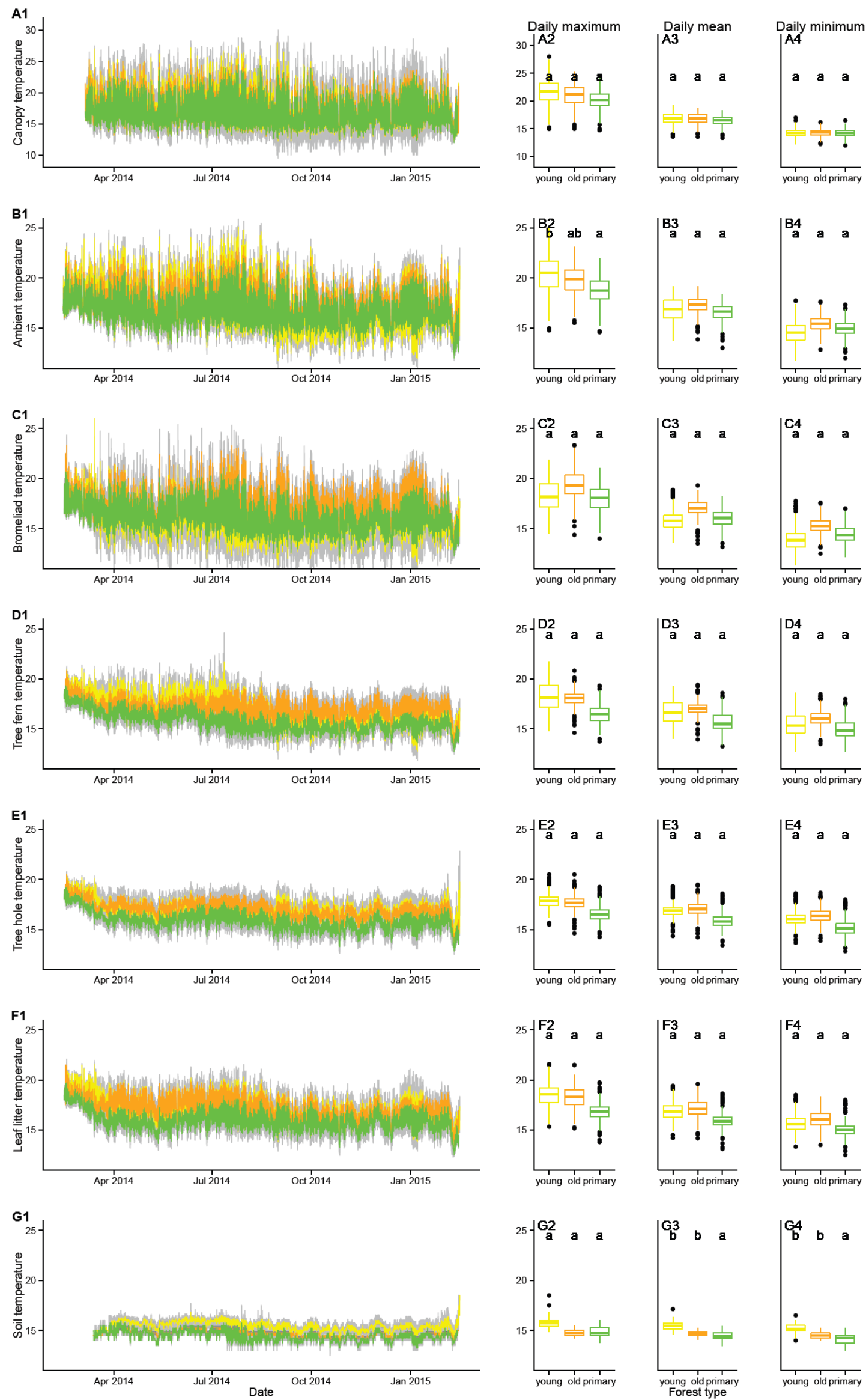


\section{References}

Alvarez, E., A. Duque, et al. (2012). "Tree above-ground biomass allometries for carbon stocks estimation in the natural forests of Colombia." Forest Ecology and Management 267: 297308.

Asner, G. P., T. K. Rudel, et al. (2009). "A Contemporary Assessment of Change in Humid Tropical Forests." Conservation Biology 23(6): 1386-1395.

Barlow, J., T. A. Gardner, et al. (2007). "Quantifying the biodiversity value of tropical primary, secondary, and plantation forests." Proceedings of the National Academy of Sciences 104(47): 18555-18560.

Barthlott, W., V. Schmit-Neuerburg, et al. (2001). "Diversity and abundance of vascular epiphytes: a comparison of secondary vegetation and primary montane rain forest in the Venezuelan Andes." Plant Ecology 152(2): 145-156.

Benzing, D. H. (2000). Bromeliaceae: Profile of an adaptive radiation. Cambridge, Cambridge University Press.

Bittner, J. and S. W. Breckle (1995). "THE GROWTH-RATE AND AGE OF TREE FERN TRUNKS IN RELATION TO HABITATS." American Fern Journal 85(2): 37-42.

Bluhm, C., S. Scheu, et al. (2015). "Oribatid mite communities on the bark of dead wood vary with log type, surrounding forest and regional factors." Applied Soil Ecology 89(0): 102-112.

Cadavid, J. G., C. Roman-Valencia, et al. (2005). "Composición y estructura de anfibios anuros en un transecto altitudinal de los Andes Centrales de Colombia." Revista del Museo Argentino de Ciencias Naturales 7(2): 113-118.

Cairns, M. A., S. Brown, et al. (1997). "Root biomass allocation in the world's upland forests." Oecologia 111(1): 1-11.

CBD (2011). REDD-plus and Biodiversity. CBD Technical Series No. 59. Montreal, Secretariat of the Convention on Biological Diversity; United Nations Environment Programme: 68.

Chave, J., C. Andalo, et al. (2005). "Tree allometry and improved estimation of carbon stocks and balance in tropical forests." Oecologia 145(1): 87-99.

Chazdon, R. (2014). Second Growth: The promise of tropical forest regeneration in an age of deforestation. Chicago, USA, University of Chicago Press.

Chen, I.-C., J. K. Hill, et al. (2011). "Rapid Range Shifts of Species Associated with High Levels of Climate Warming." Science 333(6045): 1024-1026.

Chen, I.-C., H.-J. Shiu, et al. (2009). "Elevation increases in moth assemblages over 42 years on a tropical mountain." Proceedings of the National Academy of Sciences 106(5): 1479-1483.

dos Santos Bastos, A. H. and A. Y. Harada (2011). "Leaf-litter amount as a factor in the structure of a ponerine ants community (Hymenoptera, Formicidae, Ponerinae) in an eastern Amazonian rainforest, Brazil." Revista Brasileira De Entomologia 55(4): 589-596.

Edwards, D. P., A. Magrach, et al. (2014). "Selective-logging and oil palm: multitaxon impacts, biodiversity indicators, and trade-offs for conservation planning." Ecological Applications 24(8): 2029-2049.

Ellwood, M. D. and W. A. Foster (2004). "Doubling the estimate of invertebrate biomass in a rainforest canopy." Nature 429(6991): 549-551.

Feldpausch, T. R., J. Lloyd, et al. (2012). "Tree height integrated into pantropical forest biomass estimates." Biogeosciences 9(8): 3381-3403.

Ferraz, G., G. J. Russell, et al. (2003). "Rates of species loss from Amazonian forest fragments." Proceedings of the National Academy of Sciences 100(24): 14069-14073.

Fisher, B., D. P. Edwards, et al. (2011). "The high costs of conserving Southeast Asia's lowland rainforests." Frontiers in Ecology and the Environment 9(6): 329-334. 
Foster, W. A., J. L. Snaddon, et al. (2011). "Establishing the evidence base for maintaining biodiversity and ecosystem function in the oil palm landscapes of South East Asia." Philosophical Transactions of the Royal Society B: Biological Sciences 366(1582): 3277-3291.

Fountain-Jones, N. M., P. B. McQuillan, et al. (2012). "Beetle communities associated with the tree fern Dicksonia antarctica Labill. in Tasmania." Australian Journal of Entomology 51: 154-165.

Freeman, B. G. and A. M. Class Freeman (2014). "Rapid upslope shifts in New Guinean birds illustrate strong distributional responses of tropical montane species to global warming." Proceedings of the National Academy of Sciences 111(12): 4490-4494.

Gibbon, A., M. R. Silman, et al. (2010). "Ecosystem Carbon Storage Across the Grassland-Forest Transition in the High Andes of Manu National Park, Peru." Ecosystems 13(7): 1097-1111.

Gibbs, H. K., A. S. Ruesch, et al. (2010). "Tropical forests were the primary sources of new agricultural land in the 1980s and 1990s." Proceedings of the National Academy of Sciences of the United States of America 107(38): 16732-16737.

Gibson, L., T. M. Lee, et al. (2011). "Primary forests are irreplaceable for sustaining tropical biodiversity." Nature 478(7369): 378-381.

Gilroy, J. J., P. Woodcock, et al. (2014). "Cheap carbon and biodiversity co-benefits from forest regeneration in a hotspot of endemism." Nature Clim. Change 4(6): 503-507.

Grace, J., E. Mitchard, et al. (2014). "Perturbations in the carbon budget of the tropics." Global Change Biology 20(10): 3238-3255.

Grüebler, M., S. Widmer, et al. (2014). "Temperature characteristics of winter roost-sites for birds and mammals: tree cavities and anthropogenic alternatives." International Journal of Biometeorology 58(5): 629-637.

Guariguata, M. R. and R. Ostertag (2001). "Neotropical secondary forest succession: changes in structural and functional characteristics." Forest Ecology and Management 148(1-3): 185206.

Hannah, L. E. E. (2011). "Climate Change, Connectivity, and Conservation Success." Conservation Biology 25(6): 1139-1142.

Hansen, M. C., P. V. Potapov, et al. (2013). "High-Resolution Global Maps of 21st-Century Forest Cover Change." Science 342(6160): 850-853.

Hickling, R., D. B. Roy, et al. (2006). "The distributions of a wide range of taxonomic groups are expanding polewards." Global Change Biology 12(3): 450-455.

Houghton, R. A., F. Hall, et al. (2009). "Importance of biomass in the global carbon cycle." Journal of Geophysical Research-Biogeosciences 114.

Huey, R. B. and J. J. Tewksbury (2009). "Can behavior douse the fire of climate warming?" Proceedings of the National Academy of Sciences of the United States of America 106(10): 3647-3648.

IPCC (2014). Climate Change 2014: Synthesis Report. Contribution of Working Groups I, II and III to the Fifth Assessment Report of the Intergovernmental Panel on Climate Change. R. K. P. a. L. A. M. e. [Core Writing Team. Geneva, Switzerland: 151 pp.

Jocque, M. and R. Field (2014). "Aquatic invertebrate communities in tank bromeliads: how well do classic ecological patterns apply?" Hydrobiologia 730(1): 153-166.

Jordani, M. X., E. Hasui, et al. (2015). "Natural enemies depend on remnant habitat size in agricultural landscapes." Journal of Forestry Research 26(2): 469-477.

Lassauce, A., Y. Paillet, et al. (2011). "Deadwood as a surrogate for forest biodiversity: Meta-analysis of correlations between deadwood volume and species richness of saproxylic organisms." Ecological Indicators 11(5): 1027-1039.

Lawler, J. J., A. S. Ruesch, et al. (2013). "Projected climate-driven faunal movement routes." Ecology Letters 16(8): 1014-1022.

Lee-Yaw, J. A., T. H. Sechley, et al. (2015). "Conflicting effects of microhabitats on Long-toed Salamander (Ambystoma macrodactylum) movement: implications for landscape connectivity." Canadian Journal of Zoology 93(1): 1-7. 
Lewis, S. L., D. P. Edwards, et al. (2015). "Increasing human dominance of tropical forests." Science 349(6250): 827-832.

Li, Z., L.-y. Wang, et al. (2011). "Analysis on Community Diversity of Spiders from Chishui National Nature Reserve for Spinulose Tree Fern, Guizhou Province." Sichuan Journal of Zoology 30(6): 972-976.

Lindsell, J. A., D. C. Lee, et al. (2015). "Availability of large seed-dispersers for restoration of degraded tropical forest." Tropical Conservation Science 8(1): 17-27.

Maanavilja, L., K. Aapala, et al. (2014). "Impact of drainage and hydrological restoration on vegetation structure in boreal spruce swamp forests." Forest Ecology and Management 330: 115-125.

MacArthur, R. H., J. W. MacArthur, et al. (1962). "On bird species diversity II. Prediction of bird census from habitat measurements." Amer Nat 98((888)): 167-174.

Maclean, I. M. D. and R. J. Wilson (2011). "Recent ecological responses to climate change support predictions of high extinction risk." Proceedings of the National Academy of Sciences 108(30): 12337-12342.

Martin, P. A., A. C. Newton, et al. (2013). "Carbon pools recover more quickly than plant biodiversity in tropical secondary forests." Proceedings of the Royal Society B: Biological Sciences 280(1773).

McCracken, S. F. and M. R. Forstner (2014). "Oil road effects on the anuran community of a high canopy tank bromeliad (Aechmea zebrina) in the upper Amazon basin, Ecuador." PLoS One 9(1): e85470.

McGarvey, J. C., J. R. Thompson, et al. (2015). "Carbon storage in old-growth forests of the MidAtlantic: toward better understanding the eastern forest carbon sink." Ecology 96(2): 311317.

McGlynn, T. P. and S. E. Kirksey (2000). "The effects of food presentation and microhabitat upon resource monopoly in a ground-foraging ant (Hymenoptera: Formicidae) community." Rev Biol Trop 48(2-3): 629-641.

MEA (2005). Ecosystems and human well-being: Synthesis. I. Press. Washington, D.C.

Merrifield, K. and L. Royce (2002). Invertebrate Communities in Mosses. Proceedings of the 2002 Invertebrates in Captivity Conference, Tucson, Arizona.

Michel, A. K. and S. Winter (2009). "Tree microhabitat structures as indicators of biodiversity in Douglas-fir forests of different stand ages and management histories in the Pacific Northwest, USA." Forest Ecology and Management 257(6): 1453-1464.

Morueta-Holme, N., K. Engemann, et al. (2015). "Strong upslope shifts in Chimborazo's vegetation over two centuries since Humboldt." Proceedings of the National Academy of Sciences 112(41): 12741-12745.

Myers, N., R. A. Mittermeier, et al. (2000). "Biodiversity hotspots for conservation priorities." Nature 403(6772): 853-858.

Nadkarni, N. M. (2000). "Colonization of stripped branch surfaces by epiphytes in a lower montane cloud forest, Monteverde, Costa Rica." Biotropica 32(2): 358-363.

Nascimento, H. E. M. and W. F. Laurance (2002). "Total aboveground biomass in central Amazonian rainforests: a landscape-scale study." Forest Ecology and Management 168(1-3): 311-321.

Oldekop, J. A., A. J. Bebbington, et al. (2012). "Co-Occurrence Patterns of Common and Rare LeafLitter Frogs, Epiphytic Ferns and Dung Beetles across a Gradient of Human Disturbance." PLoS One 7(6): e38922.

Orme, C. D. L., R. G. Davies, et al. (2005). "Global hotspots of species richness are not congruent with endemism or threat." Nature 436(7053): 1016-1019.

Panizzo, J. U. (2011). Physical factors influencing macro-invertebrate assemblages in epiphytic bromeliads in the rainforest of Belize. Department of International Environment and Development Studies. As, Norwegian University of Life Sciences. Master: 37. 
Parmesan, C. and G. Yohe (2003). "A globally coherent fingerprint of climate change impacts across natural systems." Nature 421(6918): 37-42.

Phelps, J., D. A. Friess, et al. (2012). "Win-win REDD+ approaches belie carbon-biodiversity tradeoffs." Biological Conservation 154: 53-60.

Poorter, L., F. B. Ongers, et al. (2016). "Biomass resilience of Neotropical secondary forests." Nature 530(7589): 211-+.

Queiroz, A. C. M., C. R. Ribas, et al. (2013). "Microhabitat Characteristics that Regulate Ant Richness Patterns: The Importance of Leaf Litter for Epigaeic Ants." Sociobiology 60(4): 367-373.

Queiroz, C., R. Beilin, et al. (2014). "Farmland abandonment: threat or opportunity for biodiversity conservation? A global review." Frontiers in Ecology and the Environment 12: 288-296.

Richards, S. J. e. (2007). "A rapid biodiversity assessment of the Kaijende Highlands, Enga Province, Papua New Guinea." RAP Bulletin of Biological Assessment 45: 1-96.

Rodríguez, N., D. Armenteras, et al. (2012). "Land use and land cover change in the Colombian Andes: dynamics and future scenarios." Journal of Land Use Science: 1-21.

Ruiz-Jaen, M. and T. M. Aide (2004). Recovery of ecological integrity following forest restoration. 16 th Int'l Conference, Society for Ecological Restoration. Victoria, Canada.

Ruiz, D., D. G. Martinson, et al. (2012). "Trends, stability and stress in the Colombian Central Andes." Climatic Change 112(3-4): 717-732.

Sanchez-Cuervo, A. M. and T. M. Aide (2013). "Consequences of the Armed Conflict, Forced Human Displacement, and Land Abandonment on Forest Cover Change in Colombia: A Multi-scaled Analysis." Ecosystems 16(6): 1052-1070.

Scheffers, B. R., R. M. Brunner, et al. (2013). "Thermal Buffering of Microhabitats is a Critical Factor Mediating Warming Vulnerability of Frogs in the Philippine Biodiversity Hotspot." Biotropica 45(5): 628-635.

Scheffers, B. R., D. P. Edwards, et al. (2014). "Microhabitats reduce animal's exposure to climate extremes." Global Change Biology 20(2): 495-503.

Scheffers, B. R., B. L. Phillips, et al. (2013). "Increasing arboreality with altitude: a novel biogeographic dimension." Proceedings of the Royal Society of London B: Biological Sciences 280(1770).

Scheffers, B. R., B. L. Phillips, et al. (2014). "Asplenium bird's nest ferns in rainforest canopies are climate-contingent refuges for frogs." Global Ecology and Conservation 2(0): 37-46.

Schnell, J. K., G. M. Harris, et al. (2013). "Estimating extinction risk with metapopulation models of large-scale fragmentation." Conserv Biol 27(3): 520-530.

Schulze, E. D., E. Beck, et al. (2005). Plant Ecology, Springer-Verlag Berlin Heidelberg.

Sekercioglu, C. H., S. H. Schneider, et al. (2008). "Climate change, elevational range shifts, and bird extinctions." Conserv Biol 22(1): 140-150.

Shi, H., D. Paull, et al. (2014). "Thermal buffering effect of alpine boulder field microhabitats in Australia: Implications for habitat management and conservation." Biological Conservation 180: 278-287.

Shuter, E. and M. Westoby (1992). "Herbivorous arthropods on bracken (Pteridium aquilinum (L.) Khun) in Australia compared with elsewhere." Australian Journal of Ecology 17(3): 329-339.

Sierra, C. A., J. I. del Valle, et al. (2007). "Total carbon stocks in a tropical forest landscape of the Porce region, Colombia." Forest Ecology and Management 243(2-3): 299-309.

Silva, B. and A. Piratelli (2014). "Foraging behaviour of the Scale-throated Hermit Phaethornis eurynome Lesson, 1832 (Aves, Trochilidae) in Vriesea incurvata Gaudich (Bromeliaceae)." Brazilian Journal of Biology 74: 311-314.

Silva, H. R. d., A. L. G. d. Carvalho, et al. (2011). "Selecting a Hiding Place: Anuran Diversity and the use of Bromeliads in a Threatened Coastal Sand Dune Habitat in Brazil." Biotropica 43(2): 218-227. 
Stapp, P. (1997). "Microhabitat Use and Community Structure of Darkling Beetles (Coleoptera: Tenebrionidae) in Shortgrass Prairie: Effects of Season Shrub and Soil Type." American Midland Naturalist 137(2): 298-311.

Strassburg, B. B. N., A. Kelly, et al. (2010). "Global congruence of carbon storage and biodiversity in terrestrial ecosystems." Conservation Letters 3(2): 98-105.

Tarkowska-Kukuryk, M. and T. Mieczan (2014). "Distribution and Environmental Determinants of Chironomids (Diptera, Chironomidae) in Sphagnum Microhabitats." Polish Journal of Environmental Studies 23(2): 483-490.

Tiepolo, G., M. Calmon, et al. (2002). Measuring and monitoring carbon stocks at the guaraqueçaba climate action project, Paraná, Brazil. International Symposium on Forest Carbon Sequestration and Monitoring, Extension Serie Taiwan Forestry Research Institute: 98-115.

Turner, I. M., K. S. Chua, et al. (1996). "A Century of Plant Species Loss from an Isolated Fragment of Lowland Tropical Rain Forest

Un Siglo de Pérdida de Especies de Plantas en un Fragmento Aislado de Bosque Tropical Lluvioso en Tierras bajas." Conservation Biology 10(4): 1229-1244.

Urbina-Cardona, J. N., M. Olivares-Pérez, et al. (2006). "Herpetofauna diversity and microenvironment correlates across a pasture-edge-interior ecotone in tropical rainforest fragments in the Los Tuxtlas Biosphere Reserve of Veracruz, Mexico." Biological Conservation 132(1): 61-75.

Urbina, J. C. and S. P. Galeano (2009). "Abundance, activity patterns, and microhabitat of Rhinella macrorhina: An endemic toad from the cloud forests of the Colombian Central Andes." Herpetological Journal 19: 35-40.

Wanger, T. C., D. T. Iskandar, et al. (2010). "Effects of land-use change on community composition of tropical amphibians and reptiles in Sulawesi, Indonesia." Conserv Biol 24(3): 795-802.

Winter, S., M. Flade, et al. (2005). "The importance of near-natural stand structures for the biocoenosis of lowlandbeech forests." Forest Snow and Landscape Research 79(1-2): 127144.

Woods, C. L. and S. J. DeWalt (2013). "The Conservation Value of Secondary Forests for Vascular Epiphytes in Central Panama." Biotropica 45(1): 119-127.

Woziwoda, B., A. Parzych, et al. (2014). "Species diversity, biomass accumulation and carbon sequestration in the understorey of post-agricultural Scots pine forests." Silva Fennica 48(4). 